\title{
A STUDY ON READE-WESOLOWSKI CLASS OF FUNCTIONS
}

\author{
R. PARVATHAM
}

Abstract. A new class Reade-Wesolowski class- of functions is defined and the Fekete-Szegö problem for this class is studied. Also the action of Ruscheweyh integral operator on this class has been investigated and this gives an improvement of a result due to K. S. Padmanabhan and R. Bharati.

Mathematics subject classification (2000): 30C45.

Key words and phrases: Close-to-star functions, Ruscheweyh integral operator.

\section{REFERENCES}

[1] R. Bharati, On $\alpha$-Close-to-convex functions, Proc. Indian Acad. Sci. 88A, (1979), 93-103.

[2] C. CARATHÉODORY AND L. FEJÉR, Über den Zusammenhang der Extremen von harmonischen Funktionen mit ihren Koeffizienten und Über den Picard-Landauschen Satz, Rend. Circ. Mat. Palermo, 32, (1911), 193-217.

[3] N. E. CHO AND S. OWA, On the Fekete-Szegö and argument inequalities for strongly close-to-star functions, Math. Inequalities and Appl., 5, 4 (2002), 697-705.

[4] M. FEKETE AND G. SzEGÖ, Eine Bemerkunguber ungerade schlichte Funktionen , J. London Math. Soc., 8, (1933), 85-89.

[5] W. JANOWSKI, Some extremal problems for certain families of analytic functions, Bull. Acad. Polon. Sci. Ser. Sci. Phys. Astronom, 21, (1973), 17-23.

[6] S. S. Miller AND P. T. Mocanu, Differential subordinations and univalent functions, Michigan Math. J. 28, (1981), 157-171.

[7] S. S. Miller and P. T. Mocanu, Differential subordinations, Marcel Dekker Inc., New York, 1999.

[8] K. S. PADMANABHAN AND R. BHARATI, On a close-to-convex functions II, Glasnik Mathematici, 16, (1981), 235-244.

[9] R. PARVATHAm And D. J. PrabhaKaran, Some applications of differential subordinations, Kyungpook Math. J. 41, (2001), 297-288.

[10] R. PARVATHAM AND S. PONNUSAMY, Non autonomous differential inequalities in the complex plane, Mathematica (Cluj), 37, (1995), 205-213.

[11] M. O. READE, On Close-to-convex functions, Michigan Math. J. 3, (1955), 59-62.

[12] A. Wesolowski, Certain results concernant la class $S^{*}(\alpha \beta)$, Ann. Univ. Marie Curie Sklodowska, Sect. A, 25, (1971), 121-130. 